\title{
The removal of heavy metals from aqueous solution using natural Jordanian zeolite
}

\author{
Yazan Taamneh $^{1} \cdot$ Suhail Sharadqah $^{2}$
}

Received: 27 November 2015/ Accepted: 14 January 2016/Published online: 2 February 2016

(C) The Author(s) 2016. This article is published with open access at Springerlink.com

\begin{abstract}
In this article, the adsorption process of cadmium and copper using natural Jordanian (NJ) zeolite as adsorbent has been experimentally estimated. The samples of $\mathrm{NJ}$ zeolite were obtained from Al Mafraq discrete, north east of Jordan. The influence of the bulk concentration $\left(C_{\mathrm{o}}\right)$, contact time $(t)$ and different adsorbent masses $(m)$ of $\mathrm{NJ}$ zeolite on the removal of heavy metal were evaluated. These variables had a considerable function in promoting the sorption process of heavy metal using the NJ zeolite. The initial concentration of heavy metals in the stock solution was extended between 80 and $600 \mathrm{mg} / \mathrm{L}$. The batch adsorption method was employed to investigate the adsorption process. The experimental data were correlated using Freundlich and Langmuir empirical formula. The ability of NJ zeolite to eliminate cadmium and copper was estimated according to Langmuir isotherm empirical formula and found 25.9 and $14.3 \mathrm{mg} / \mathrm{g}$ for cadmium and copper, respectively. The kinetics of adsorption of cadmium and copper have been analyzed and correlated by first-order and second-order reaction model. It was noticed that adsorption of cadmium and copper was better correlated with pseudo-second-order kinetic model. The results presented that $\mathrm{NJ}$ zeolite is practical adsorbent for removing cadmium and copper ion metal.
\end{abstract}

Yazan Taamneh

ymtaamneh@just.edu.jo

1 Department of Aeronautical Engineering, Jordan University of Science and Technology, P.O. Box 3030, Irbid 22110, Jordan

2 Department of Natural Resources and Chemical Engineering, Tafila Technical University, P.O. Box 179, Tafila 66110 , Jordan
Keywords NJ zeolite $\cdot$ Batch process $\cdot$ Cadmium . Copper · Isotherm $\cdot$ Kinetic

\section{Introduction}

The major industrial sources impact the environment as a result of producing heavy metals. The existence of heavy metals in wastewater due to many manufacturing processes is a legalized problem worldwide. The most common sources of heavy metals obtained from surface finishing processes as well as industrial products that ends up in wastewater (Hui et al. 2005; Karvelas et al. 2003; Ahluwalia 2007). Removing heavy metals from industrial wastewater required high energy or special operational requirements. Several techniques such as adsorption, extraction, disambiguation, clotting, ion-exchange, and membrane processes are supposed for the handling of wastewater pollution (Babel and Kurniawan 2003a; Wang and Peng 2010a; Kwon et al. 2010). Adsorption method form an appropriate method for wastewater handling because of its cost effectiveness and simplicity, among all these methods (Gupta et al. 2006; Ali 2012; Yadanaparthi et al. 2009; Argun 2008; Rashed 2011).

Regardless of the effectiveness of activated carbon for prevailing the metal ions load, particular attention have been drawn by several inspector to the common adsorbents like silica, sand, activated alumina, clays, and natural zeolite for their relatively low costs and natural characteristics (Panayotova 2001; Bailey et al. 1999; Babel and Kurniawan 2003b). Actually, zeolite gains progressive attraction of many investigator because of its special characteristic such as ion exchange capacity, hydrationdehydration, and adsorption (Caputo and Pepe 2007; Wang and Peng 2010b; Zhang 2006).

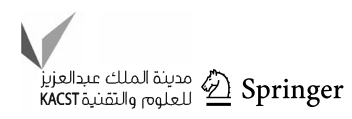


Zeolites are aluminosilicate minerals of alkali or alkaline earth metal which contains crystal water. Zeolites consist of three-dimensional networks of aluminate and silicone dioxide tetrahedral linked by partnership of all oxygen atoms. The voids make up from 20 to $50 \%$ of the total crystal volume of most zeolites. (Mumpton 1978, 1996; Gottardi 1978). For wastewater treatment, the most important properties of natural zeolite are cation exchange capacity and ion selectivity (Colella 1996).

Removing of heavy metal by natural zeolites with respect to $\mathrm{Co}^{2+}, \mathrm{Cu}^{2+}, \mathrm{Zn}^{2+}$, and $\mathrm{Mn}^{2+}$ were studied by Erdem et al. (2004). The study achieved using batch process technique and the effect of varying the initial heavy metal concentration also considered. They concluded that the adsorption process rely on bulk density and size of hydrated ion. The selectivity succession of metal ionic according to their equilibrium studies was specified like $\mathrm{Co}^{2+}>\mathrm{Cu}^{2+}>\mathrm{Zn}^{2+}>\mathrm{Mn}^{2+}$.

Loizidou and Townsend (1987) indicated that natural zeolite is able to eliminate some of heavy metals effectively from industrial wastewater. The ability of the zeolite to be regenerated is an important issue that must be well considered together with the other relevant properties such as its selectivity to eliminate heavy metals toxicity from aqueous solutions.

There are a large number of processes that have been improved and used over the years to eliminate dissolved of cadmium and copper in industrial wastewater treatment using clotting, adsorption, ion exchange, extraction, etc. (Lewinsky 2006; Blocher et al. 2003; Izanloo and Nasseri 2005; Dhaba and Hussein 2014). This conventional technique is often neither effective nor economically especially when the cadmium and copper ion metal are presented at relatively low concentration.

Recently, Rao et al. (2005) evaluated the sorption process for cadmium and copper from aqueous solutions using activated coal. The effect of initial heavy metal load, adsorbent mass, and time contacting on adsorption ability were estimated. They analyzed and correlated the experimental data according to both Freundlich and Langmuir model. The highest uptake of copper and cadmium was found to be $20 \mathrm{mg} / \mathrm{g}$ for cadmium and copper. The maximum uptake capacities of cadmium and copper were 88 and $90 \%$, respectively.

Zeolite was reported for the first time in Jebel Aritain discrete (Jordan) in 1987. Since that, various studies have been carried out to inspect the genesis applicability of $\mathrm{NJ}$ zeolites in different applications such as, water treatment, agriculture, water filter and the environmental protection (Dwiri 1987; Sharadqah and Al-Dwairi 2010).

The capability of Jordanian zeolite was studied by Marashdeh et al. (2009), to eliminate heavy metals ( $\mathrm{Cr}$ and
Cd from electroplating wastewater). Batch and continues packed column experiments were used for sorption of metal in their single and binary solution. The bulk concentration of $\mathrm{Cd}^{2+}$ and $\mathrm{Cr}^{3+}$ ranged from 50 to $75 \mathrm{mg} / \mathrm{L}$. The experimental results showed that the uptake capacities increase with initial heavy metal concentration. From the equilibrium studies the adsorption capacity of zeolite for cadmium $q_{\mathrm{e}}=25.5 \mathrm{mg} / \mathrm{g}$ was higher than that for chrome $q_{\mathrm{e}}=19.75 \mathrm{mg} / \mathrm{g}$. The uptake of both metals was decreased when combined together with equal concentration in a solution, $64 \%$ decrease for cadmium $q_{\mathrm{e}}=9.5 \mathrm{mg} / \mathrm{g}$ and $31 \%$ decrease for chromium $q_{\mathrm{e}}=13.5 \mathrm{mg} / \mathrm{g}$.

A packed bed column was constructed by Taamneh and Dwairi (2013) to estimate the capacity of NJ zeolite to bring out nickel from aqueous solutions. The NJ zeolite specimen was picked up from Jabal AL Aritayn discrete (Jordan). The experimental results of adsorption process in a packed bed column are used to bear out the accuracy of Klinkenberg correlation model. The Klinkenberg equation was employed to predict the effective diffusivity constant.

Baker et al. (2009) investigated the uptake capacity of heavy metals ions like $\mathrm{Cr}^{3+}, \mathrm{Cd}^{2+}, \mathrm{Cu}^{2+}$, and $\mathrm{Pb}^{2+}$ using $\mathrm{NJ}$ zeolite for batch and packed bed column at the following condition: $\mathrm{pH} 3.0$, volume of solution $1 \mathrm{~L}$, temperature of $25^{\circ} \mathrm{C}$ and phillipsite dose $5 \mathrm{~g}$. The Jordanian phillipsite tuff presented high selectivity for the discharge of lead about $98 \%$ achieved within 90 min, then chrome (III), copper, and cadmium about $96 \%$ removal achieved within $5 \mathrm{~h}$. The adsorption capacity of phillipsite tuff by assuming initial concentration of cadmium $30 \mathrm{mg} / \mathrm{L}$ was calculated about $0.24 \mathrm{mg} \mathrm{Cd} / \mathrm{g}$ zeolite.

As concluded from literature review, NJ zeolites have been used to eliminate different heavy metals ions from prepared synthetic solution. But there has been no effort devoted to correlate the experimental data with both sorption isotherm and kinetics model. In this work, our aim object is to investigate the adsorption process of cadmium and copper on NJ zeolite and correlate the data with wellknown isotherms and kinetic model.

\section{Materials and methods}

\section{Natural Jordanian zeolite (NJ zeolite)}

The samples of natural zeolite were picked up from AlMafraq area, northeast of Jordan. The bulk sample was washed by distilled water to eliminate most of the surface dust. Then the sample was crushed and sieved into two different grain sizes (less than $0.4 \mathrm{~mm}$ and $0.4-4 \mathrm{~mm}$ ). The experiments were performed with grain size distribution less than $0.4 \mathrm{~mm}$ in diameter. Their distribution was measured using laser diffraction instrument (see Fig. 1). 
(a)

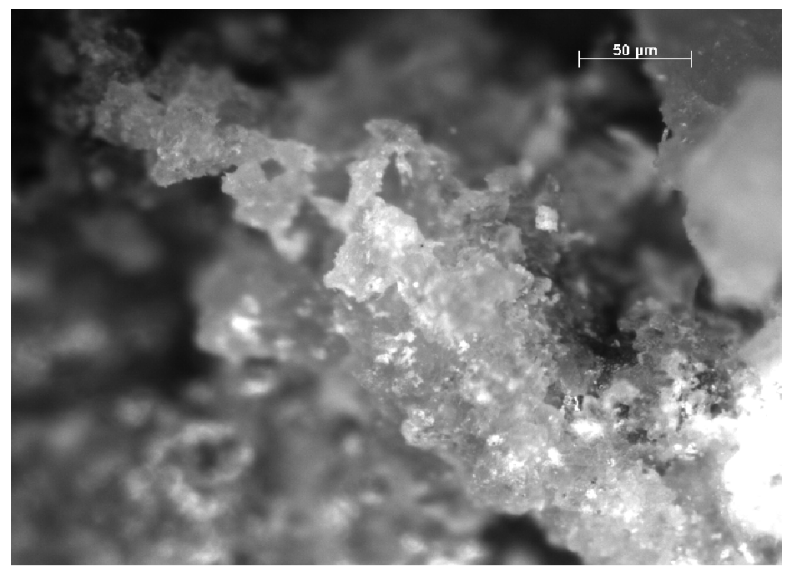

(c)

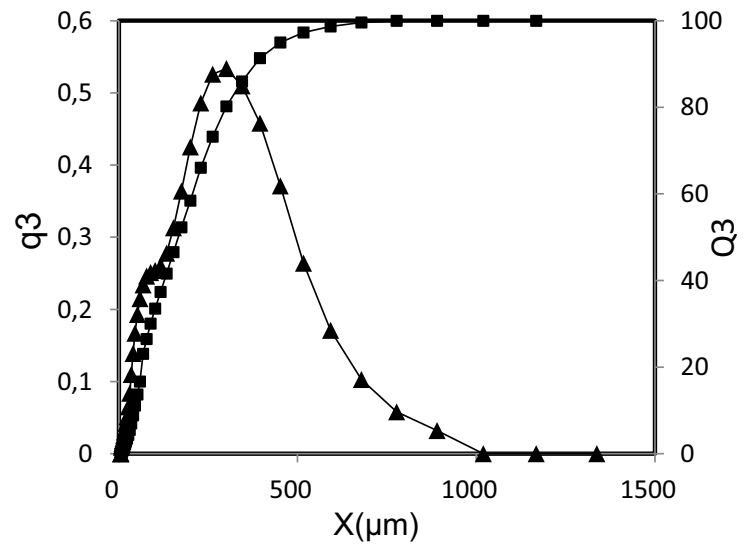

(b)

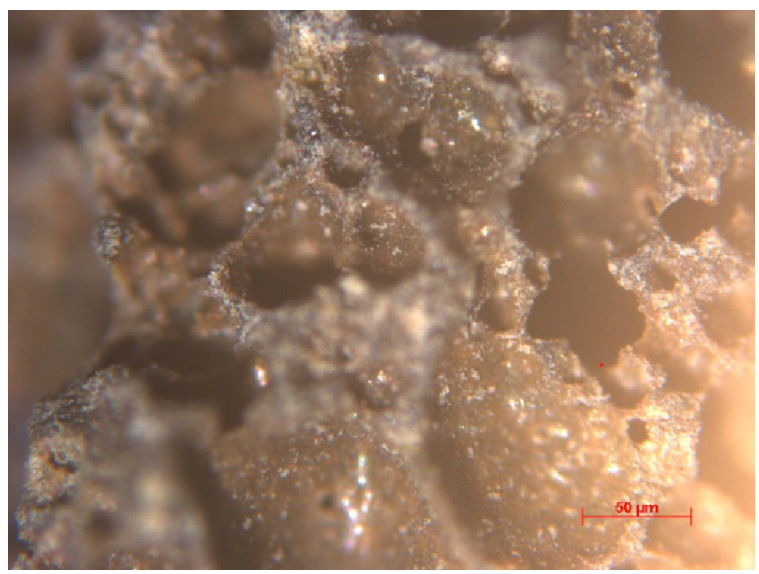

(d)

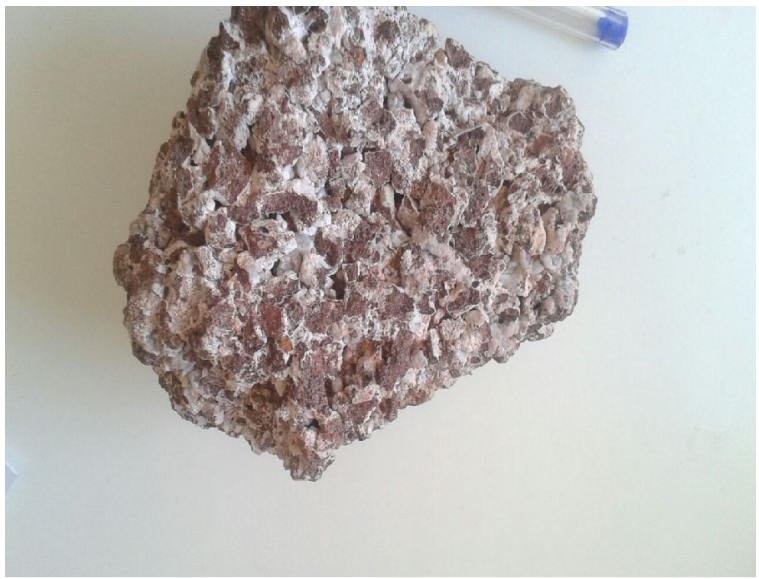

Fig. 1 a Crystallization, b pores shape, $\mathbf{c}$ particle size distribution, $\mathbf{d}$ raw materials of NJ zeolite

X-ray diffraction was obtained before and after treatment with sodium chloride. The chemical analyses composition of NJ zeolite was given by Taamneh and Dwairi (2013).

\section{Chemicals and adsorption studies}

Cadmium and copper nitrate which have been diluted in distilled water are used throughout the experiments. The chemicals and reagent were supplied from Merck (Germany) and of analytical grade using deionized water. The concentrations of cadmium and copper solutions were varied from 100 to $600 \mathrm{mg} / \mathrm{L}$ by diluting the stock solution. The ion exchange process on $\mathrm{NJ}$ zeolite was accomplished using the batch method. Throughout all the experiments, the $\mathrm{pH}$ value was adjusted and kept constant using $0.1 \mathrm{~N}$ $\mathrm{NaOH}$. The glass bottles were then put on shaker for $24 \mathrm{~h}$ to attain the equilibrium. $5 \mathrm{~g}$ of $\mathrm{NJ}$ zeolite was used in the batch adsorption experiments with $250 \mathrm{~mL}$ of solutions containing different heavy metal concentration at constant $\mathrm{pH}$. To have relatively clean samples for atomic absorption spectrometer analyses, filter paper (Whatman No. 43) was used. The concentration of metal ions in initial and final solution was measured by Atomic Absorption Spectrometer (AAS). The effects of concentration $(100-600 \mathrm{mg} / \mathrm{L}$ ), adsorption dose (5-80 g) and contact time (1-60 min) were estimated.

\section{Sorption isotherm models}

In this work, the batch adsorption technique was selected to study the adsorption and kinetic models for cadmium and copper uptake. The adsorption experimental results of cadmium and copper on NJ zeolite were analyzed according to well-known isotherm model (Freundlich and Langmuir). The uptake of heavy metal through a sequence of batch test was calculated using the following equation: 
$q_{\mathrm{e}}=\frac{C_{\mathrm{o}}-C_{\mathrm{e}}}{m / V}$

where $q_{\mathrm{e}}$ is the weight of heavy metal uptake per unit of NJ zeolite $(\mathrm{mg} / \mathrm{g}) ; C_{\mathrm{o}}$ and $C_{\mathrm{e}}$ are the initial and equilibrium concentration in the samples $(\mathrm{mg} / \mathrm{L})$, respectively; $m$ is the adsorbent mass $(\mathrm{mg})$ and $V$ is the aqueous volume (L).

\section{Kinetic studies}

The sorption kinetic results of cadmium and copper on the NJ zeolite were analyzed according to first and second sorption kinetic equation (Sevil and Bilge 2007). Samples were sucked from the glass bottle every 2 min using glass syringe. The remaining of cadmium and copper concentration in the solution was also analyzed by AAS (atomic absorption spectrophotometer).

\section{Results and discussion}

\section{Effect of metal concentration}

To find the optimum concentration, experimental studies were carried out for a wide range of metal concentrations between 100 and $600 \mathrm{mg} / \mathrm{L}$. The capability of sorption process was found to be stable and reached a maximum value at concentration $100 \mathrm{mg} / \mathrm{L}$. This is because the surface where the adsorption occurs reaches its maximum uptake, i.e. no more metal ions can be adsorbed. It is also clear from Fig. 2 that the percentage of $\mathrm{Cd}$ and $\mathrm{Cu}$ removal decreases by increasing initial metal concentration. This result pointed out that with increasing metal concentration less favorable spaces become involved in the aqueous solution.

In this study the metal ion uptake could be referred to ion-exchange kinetics in the micro porous of NJ zeolite.

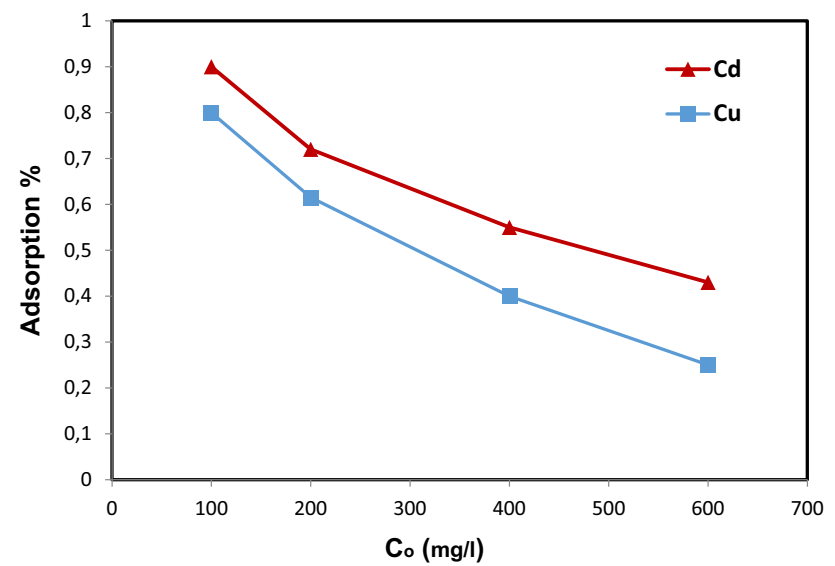

Fig. 2 Removal efficiency of heavy metal $(\mathrm{Cd}$ and $\mathrm{Cu})$ on $\mathrm{NJ}$ zeolite. $m_{\mathrm{z}}=5 \mathrm{~g}, V=250 \mathrm{ml}, \mathrm{pH} 6$, time $24 \mathrm{~h}$
Metal ions had to move through the pores of the zeolite mass as well as through channels of the lattice during the ion-exchange process and they had to substitute their cations. The adsorption percentage was larger for cadmium compared with copper.

\section{Effect of NJ zeolite volume}

The effect of NJ zeolite load on the uptake efficiency of cadmium and copper is presented in Fig. 3. The amount of zeolite required for quantitative removal of cadmium and copper from an initial metal concentration $7 \mathrm{mg} / \mathrm{L}$ was found to be $30 \mathrm{mg}$.

The adsorption percentage increased with zeolite mass in case of both cadmium and copper and when the adsorbent reaches beyond $30 \mathrm{mg}$ became steady. The adsorption percentage was found to be $46,15.5 \%$ in the case of cadmium and copper, respectively, for identical zeolite dose $(1 \mathrm{mg})$. It is clear that the uptake efficiency of cadmium and copper increases with the concentration of $\mathrm{NJ}$ zeolite. The reason for this may be the surface area of the zeolite at higher mass concentration of zeolite is more available. Therefore, the heavy metal ions have the possibility to exchange their sites over a large available surface area.

\section{Effect of contact time}

The effect of contact time on adsorption efficiency is depicted in Fig. 4. It is clear from Fig. 4 that the contact time needed to reach the maximum removal of metal by $\mathrm{NJ}$ zeolite was dependent on the type of heavy metal. From the economic system point of view, the role of the equilibrium time assessment is very important especially in many wastewater treatment applications. The equilibrium adsorption was attained through 20 min for both cadmium

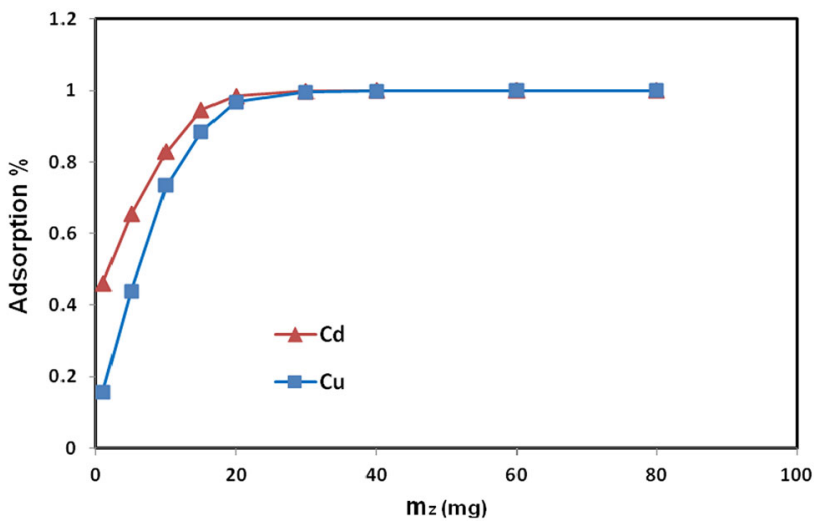

Fig. 3 Heavy metal removal $(\mathrm{Cd}$ and $\mathrm{Cu})$ as a function adsorbent dose (NJ zeolite). $C_{\mathrm{o}}=7 \mathrm{mg} / \mathrm{L}, V=25 \mathrm{~mL}, \mathrm{pH} 6$, time $24 \mathrm{~h}$ 


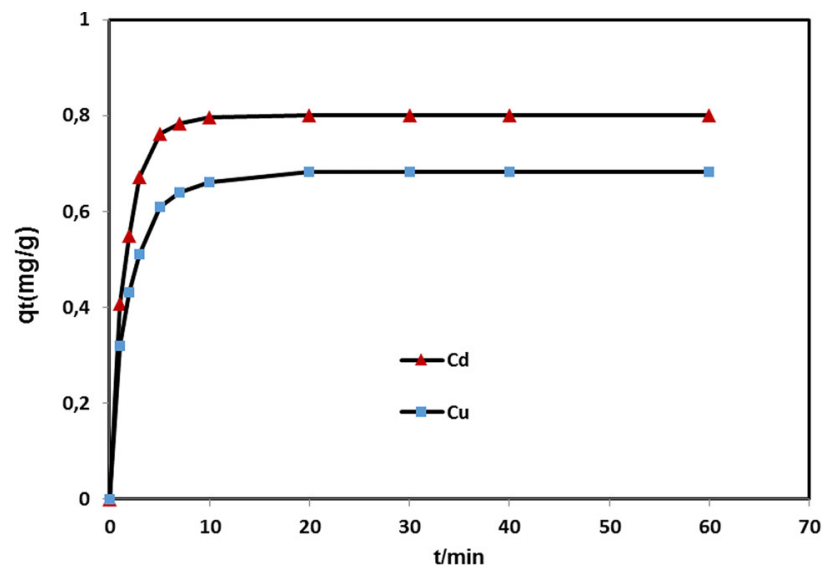

Fig. 4 Variation of heavy metal removal $(\mathrm{Cd}, \mathrm{Cu})$ on $\mathrm{NJ}$ zeolite as function of contact time: $C_{\mathrm{o}}=7 \mathrm{mg} / \mathrm{L}, V=25 \mathrm{ml}, \mathrm{pH} 6$, time $24 \mathrm{~h}$

and copper metal and the equilibrium adsorption were determined at 80 and $68 \mathrm{mg} / \mathrm{g}$ (Fig. 4).

\section{Adsorption isotherms}

\section{Freundlich empirical equation}

Although the model was first proposed extensively as an empirical equation by Freundlich (1932), many other researchers used it. Currently, Freundlich model is used in organic compounds or high-selectivity species on activated charcoal and molecular sieves. Freundlich empirical can be given by:

$q_{\mathrm{e}}=k_{\mathrm{F}} C_{\mathrm{e}}^{1 / n}$

The parameters $k_{\mathrm{F}}$ and $1 / n$ are Freundlich constant and sorption intensity, respectively, and these two parameters are dependent on temperature. By taking the natural logarithm of both side of Eq. 2 we get:

$\log q_{\mathrm{e}}=\log k_{\mathrm{F}}+\frac{1}{n} \log C_{\mathrm{e}}$

The two parameters of Freundlich model can be calculated for cadmium and copper from the slope and intercept of the linear plot (see Table 1). The experimental data are fitted according to the linear form of Eq. (2).

$q_{\mathrm{e}}=20 C_{\mathrm{e}}^{5.25} \quad r^{2}=0.98$ for $\mathrm{Cd}$

$q_{\mathrm{e}}=11 C_{\mathrm{e}}^{4.4} \quad r^{2}=0.96$ for $\mathrm{Cu}$

\section{Langmuir equation}

Langmuir models primarily developed to demonstrate gassolid phase adsorption onto activated charcoal and it has conventionally been used to assess the performance of different adsorption systems including solid liquid systems. Langmuir model supposes monolayer adsorption, i.e. all
Table 1 Freundlich and Langmuir constant

\begin{tabular}{lll}
\hline & Cadmium & Copper \\
\hline \multicolumn{2}{c}{ Freundlich isotherm constant } & \\
$K_{\mathrm{F}}$ & 20 & 11 \\
$n$ & 5.2 & 4.4 \\
$r^{2}$ & 0.98 & 0.97 \\
Langmuir isotherm constant & \\
$Q_{\mathrm{m}}$ & 25.9 & 14.3 \\
$k$ & 9.5 & 7.36 \\
$r^{2}$ & 0.97 & 0.98 \\
\hline
\end{tabular}

the adsorbed molecules are in contact with the surface layer of the adsorbent. This model is presented by:

$q_{\mathrm{e}}=\frac{Q_{\mathrm{m}} k C_{\mathrm{e}}}{1+k C_{\mathrm{e}}}$

where $q_{\mathrm{e}}$ and $C_{\mathrm{e}}$ are the equilibrium concentration of cadmium or copper in the JN zeolite and aqueous solution in $\mathrm{mg} / \mathrm{g}$ and $\mathrm{mg} / \mathrm{L}$, respectively, $Q_{\mathrm{m}}$ is the sorption capacity, $k$ is the energy of sorption constant. The linear form of Langmuir isotherm equation is given by:

$\frac{C_{\mathrm{e}}}{q_{\mathrm{e}}}=\frac{1}{k Q_{\mathrm{m}}}+\frac{C_{\mathrm{e}}}{Q_{\mathrm{m}}}$

The Langmuir isotherm linear equation for cadmium and copper adsorption on $\mathrm{NJ}$ zeolite is given by:

$\frac{C_{\mathrm{e}}}{q_{\mathrm{e}}}=0.00421+0.04 C_{\mathrm{e}} \quad r^{2}=0.98$ for $\mathrm{Cd}$

$\frac{C_{\mathrm{e}}}{q_{\mathrm{e}}}=0.0095+0.0699 C_{\mathrm{e}} \quad r^{2}=0.97$ for $\mathrm{Cu}$

The Freundlich and Langmuir isotherm parameters and the statistical fits of cadmium and copper adsorption using NJ Zeolite are presented in Table 1. It is very important to analyze the experimental data in terms of Langmuir and Freundlich isotherm sorption models. The sorption constant and regression coefficient for both Freundlich and Langmuir sorption model are given in Table 1. The comparison between the experimental adsorption results with the empirical isotherm models (Freundlich and Langmuir model) on cadmium and copper using NJ zeolite sorbent are depicted in Fig. 5. It can be noted from Fig. 5 that the adsorption experimental results are better fitted to Freundlich isotherm model than to Langmuir isotherm model. The calculated sorption capacities for cadmium and copper fitted to Langmuir linear equation were 25.9 and $14.3 \mathrm{mg} / \mathrm{g}$, respectively. The parameters $k_{\mathrm{F}}$ and $n$ were calculated by linear Freundlich equation from experimental sorption data as 20, 5.2 for cadmium and 11, 4.4 for copper (see Table 1). 


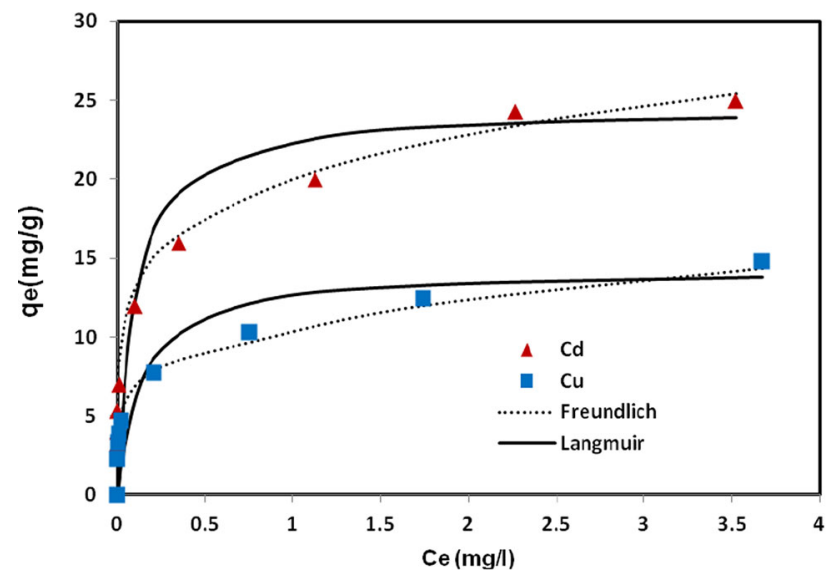

Fig. 5 Adsorption isotherms experimental data of cadmium and copper on NJ zeolite compared with Freundlich and Langmuir isotherm model at the same condition

\section{Sorption kinetic models}

The amount of cadmium and copper adsorbed, $q_{\mathrm{t}}$, at time $t$ was calculated from the following equation:

$q_{\mathrm{t}}=\frac{C_{\mathrm{o}}-C_{\mathrm{e}}}{m / V}$

The removal of copper and cadmium from zeolite as a function of time can be mathematically expressed in terms of different kinetic adsorption models such as:

\section{Pseudo-first-order kinetic model (Langerhans rate equation)}

Pseudo-first-order kinetic model supposes that the rate of change of adsorbate uptake with time is directly proportional to the difference in the equilibrium concentration and the amount of adsorbate uptake with time (Ho and McKay 1998). The kinetic rate in differential form Eq. (11) and after integration Eq. (12) is obtained:

$\frac{\mathrm{d} q_{\mathrm{t}}}{\mathrm{d} t}=k_{1}\left(q_{\mathrm{e}}-q_{\mathrm{t}}\right)$

$\ln \left(q_{\mathrm{e}}-q_{\mathrm{t}}\right)=-k_{1} t+\ln q_{\mathrm{e}}$

\section{Pesudo-second-order kinetic model}

In this model (Ho et al. 1996), the kinetic rate in differential form and it is analytical solution can be expressed as

$\frac{\mathrm{d} q_{\mathrm{t}}}{\mathrm{d} t}=k_{2}\left(q_{\mathrm{e}}-q_{\mathrm{t}}\right)^{2}$

$\frac{t}{q_{\mathrm{t}}}=\frac{1}{k_{2} q_{\mathrm{e}}^{2}}+\frac{t}{q_{\mathrm{e}}}$

To estimate the adsorption rate constant of cadmium and copper, the first-order model was used. The rate constant

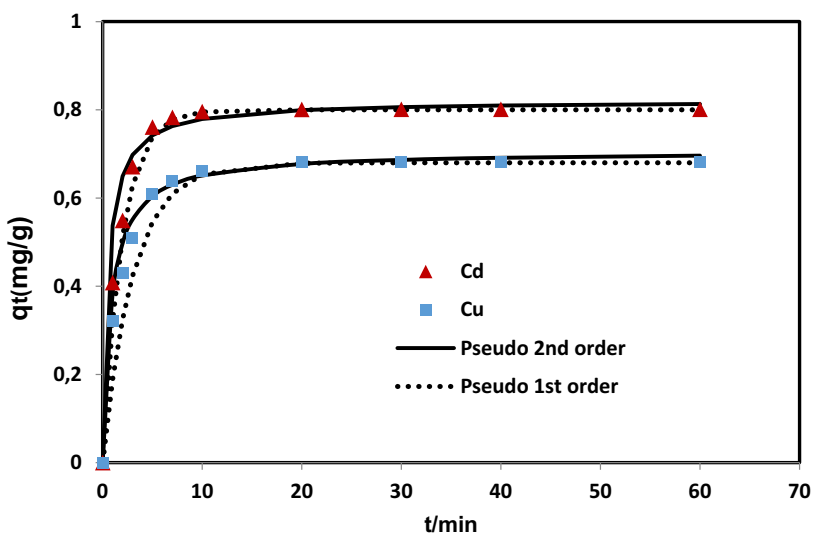

Fig. 6 Sorption kinetic experimental data of cadmium and copper on NJ zeolite compared with first- and second-order model at the same condition

$\left(k_{1}\right)$ for cadmium and copper adsorption onto $\mathrm{NJ}$ zeolite were $0.5145,0.325$, respectively. Meanwhile the secondorder reaction rate constant $\left(k_{2}\right)$ for cadmium and copper adsorption onto NJ zeolite were 2.32145, 1.716, respectively.

The time dependency of removal rate of cadmium and copper on NJ zeolite are shown in Fig. 6. The kinetic rate study of cadmium and copper on $\mathrm{NJ}$ zeolite was carried out with different time, at room temperature $22^{\circ} \mathrm{C}$, constant metal concentration $250 \mathrm{mg} / \mathrm{L}, 80 \mathrm{~g}$ of $\mathrm{NJ}$ zeolite and $\mathrm{pH}$ 6. The value of the first and second reaction rate constant $\left(k_{1}, k_{2}\right)$ obtained from sorption kinetic models are used to correlate experimental data on NJ zeolite. It can be noted that the second reaction constant has higher value for the sorption kinetic of cadmium and copper on $\mathrm{NJ}$ zeolite. It is clear from values of second-order constant that cadmium and copper sorption onto the $\mathrm{NJ}$ zeolite follows the second-order model. Thus, rate of sorption according to the second-order model for cadmium and copper are faster than first-order model. For example, the cadmium uptake capacities were completed within $10 \mathrm{~min}$. Meanwhile, the copper uptake capacity completed within $20 \mathrm{~min}$. Figure 6 shows that cadmium metal has higher uptake capacity than copper. As a result of sorption kinetic, the second-order model can demonstrate the sorption process and very well correlated with the experimental results. Therefore, the second-order equation is valuable for the kinetic sorption studied in this work.

\section{Conclusion}

The adsorption capacity of cadmium and copper using $\mathrm{NJ}$ zeolite has been experimentally investigated. It was concluded that metal bulk concentration, adsorption time and mass of adsorbent, are an important factors that affect the 
adsorption process. These parameters had a considerable trace on the uptake of cadmium and copper metal using NJ zeolite. A widely used isotherm and kinetic models to present study to estimate the equation parameters were employed.

The Freundlich and Langmuir isotherms models are used to describe the experimental adsorption results meanwhile the pseudo-first- and second-order kinetics model are used for kinetic rate elaboration. It was set that the Freundlich empirical is well demonstrated and fitting the experimental results. The metal ion uptake capacities for cadmium and copper were 25.9 and $14.3 \mathrm{mg} / \mathrm{g}$, respectively. The calculated adsorption intensity parameter correlated to Langmuir isotherm model for cadmium and copper are 9.5 and 7.36, respectively. Cadmium and copper adsorption from aqueous solution using $\mathrm{NJ}$ zeolite was well demonstrated with the second-order kinetic model. The experimental adsorption data were better adequate to the second-order model than to the first-order model. As a result of this study, the $\mathrm{NJ}$ zeolite for the removal of cadmium and copper using a batch adsorption technique has inherent advantages.

Open Access This article is distributed under the terms of the Creative Commons Attribution 4.0 International License (http:// creativecommons.org/licenses/by/4.0/), which permits unrestricted use, distribution, and reproduction in any medium, provided you give appropriate credit to the original author(s) and the source, provide a link to the Creative Commons license, and indicate if changes were made.

\section{References}

Ahluwalia SS, Goyal D (2007) Microbial and plant derived biomass for removal of heavy metals from wastewater. Bioresour Technol 98:98-2243

Ali I, Asim M, Khan TA (2012) Low cost adsorbents for the removal of organic pollutants from wastewater. J Environ Manage 113:170-183

Argun ME (2008) Use of clinoptilolite for the removal of nickel ions from water: kinetics and thermodynamics. J Hazard Mater 150:587-595

Babel S, Kurniawan TA (2003) Low-cost adsorbents for heavy metals uptake from contaminated water: a review. J Hazard Mater B 97(219):243

Bailey SE, Olin TJ, Bricka RM, Adrian DD (1999) A review of potentially low cost sorbents for heavy metals. Water Res 33:2469-2479

Baker H, Massadeh A, Younes H (2009) Natural Jordanian zeolite: removal of heavy metal ions from water samples using column and batch methods. Environ Monit Assess 157:319-330

Blocher C, Dorda J, Marrov V, Chemiel H, Lazaridis NK, Matis KA (2003) Hybrid flotation-membrane filtration process for the removal of heavy metal ions from wastewater. Water Res 37:4108-4126

Caputo D, Pepe F (2007) Experiments and data processing of ion exchange equilibria involving Italian natural zeolites: a review. Micropor Mesopor Mater 105:222-231
Colella C (1996) Ion exchange equilibria in zeolites minerals. Mineral Deposita 31:554-562

Dwiri I (1987) A chemical study of the Palagonitic Tuff of Artian area of Jordan with special references to nature, origin and industrial potential of associated zeolite deposits. $\mathrm{PhD}$ Thesis, Hull University

Erdem E, Karapinar N, Donat R (2004) The removal of heavy metal cations by natural zeolites. J Coll Inter Sci 280:309-314

Gottardi G, Galli E (1978) Natural Zeolites. SpringerVerlag, Berlin, Heidelberg, pp 200-214

Gupta VK, Mittal A, Jain R, Mathur M, Sikarwar S (2006) Adsorption of Safranin-T from wastewater using waste materials- activated carbon and activated rice husks. J Colloid Interface Sci 303:80-86

Ho YS, McKay G (1998) Sorption of dye from aqueous solution by peat. Chem Eng J 70:115-124

Ho YS, Wase DAJ, Forster CF (1996) Kinetic studies of competitive heavy metal adsorption by sphagnum moss peat. Environ Technol 17:71-77

Hui KS, Chao CYH, Kot SC (2005) Removal of mixed heavy metal ions in wastewater by zeolite $4 \mathrm{~A}$ and residual products from recycled coal fly ash. J Hazard Mater B 127:89-101

Ibrahim KM, Nasser Ed-Deen T, Khoury H (2002) Use of natural chabazitephillipsite tuff in wastewater treatment from electroplating factories in Jordan. Environ Geol 41(5):547-551

Izanloo $\mathrm{H}$, Nasseri $\mathrm{S}$ (2005) Cadmium removal from aqueous solution by ground pine core. Iranian J Eng Health Sci Eng 2(1):33-42

Karvelas M, Katsoyiannis A, Samara C (2003) Occurrence and fate of heavy metals in the wastewater treatment process. Chemosphere 53:1201-1210

Kwon JS, Yun ST, Lee JH, Kim SO, Jo HY (2010) Removal of divalent heavy metals $(\mathrm{Cd}, \mathrm{Cu}, \mathrm{Pb}$, and $\mathrm{Zn})$ and arsenic(III) from aqueous solutions using scoria:kinetics and equilibria of sorption. J Hazard Mater 174:307-313

Lewinsky AA (2006) Hazardous materials and wastewater: treatment, removal and analysis. Nova Science Pub Inc., pp 182-276

Loizidou M, Townsend RP (1987) Ion exchange properties of natural clinoptilolite, ferrierte and mordenite: Part 2. Lead-sodium and lead-ammonium equilibria. Zeolites 7:153-159

Marashdeh M, Al-Haj-Ali M (2009) Uptake of Cd (II) using natural zeolite: batch and continuous fixed-bed studies. J Eng Res $6: 1-11$

Mumpton FA (1978) Natural zeolites: occurence, properties, use. In: Sand LB, Mumpton FA (eds) Natural zeolites: a new industrial mineral commodity. Pergamon Press, Elmsford, pp 3-29

Mumpton, F.A. 1996, The natural zeolite story. In: Colella C (ed) Proceedings of the 3rd National Congress-AIMAT, omaggio scientifico a Riccardo Sersale De Frede, Napoli, Italy pp 31-64

Nevenka R, Djordje S, Mina J, Natasa ZL, Matjaz M, Venceslav K (2010) Removal of nickel(II) ions from aqueous solutions using the natural clinoptilolite and preparation of nano- $\mathrm{NiO}$ on the exhausted clinoptilolite. Appl Surf Sci 257(1524-1532):7

Panayotova M (2001) Kinetics and thermodynamics of removal of nickel ions from wastewater by use of natural and modified zeolite. Fresen Environ Bull 10:267-272

Rao M, Ramesh A, Rao G, Seshaiah K (2005) Removal of copper and cadmium from the aqueous solutions by activated carbon derived from Ceibapentandra hulls. J Hazard Mater 129:123-129

Rashed MN (2011) Acid dye removal from industrial wastewater by adsorption on treated sewage sludge. Int J Environ Waste Manag 7(1-2):175-191

Sharadqah S, Al-Dwairi R (2010) Control of Odorants Emissions from Poultry Manure Using Jordanian Natural Zeolites. Jordan J Civil Eng 4(4)

Taamneh Y, Al Dwairi R (2013) The efficiency of Jordanian natural zeolite for heavy metals removal. Appl Water Sci 3:77-84 
Wang S, Peng Y (2010) Natural zeolites as effective adsorbents in water and wastewater treatment. Chem Eng J 156:11-24

Yadanaparthi SKR, Graybill D, Wandruszka R (2009) Adsorbents for the removal of arsenic, cadmium, and lead from contaminated waters. J Hazard Mater 171:1-15

Zhang YS (2006) Development of heavy metal adsorbed by granulation of natural Zeolite. 18th World Congress of Soil Science, Philadelphia
Sevil V, Bilge A (2007) Adsorption of copper and zinc from aqueous solutions by using natural clay. J Hazard Mater 149(1):226-233 Freundlich H (1932) Kapillarchemie II, Leipzig, p 387 